\title{
Peaceable Schools: Bringing Positive Behavior Support into Utah Public Education
}

\author{
Paul Caldarella \\ Paul_Caldarella@byu.edu \\ K. Richard Young \\ Richard_Young@byu.edu
}

Follow this and additional works at: https://scholarsarchive.byu.edu/facpub

Part of the Teacher Education and Professional Development Commons

Original Publication Citation

Rocky Mountain Psychological Association, Park City, UT. (April 26)

\section{BYU ScholarsArchive Citation}

Caldarella, Paul and Young, K. Richard, "Peaceable Schools: Bringing Positive Behavior Support into Utah Public Education" (2006). Faculty Publications. 1284.

https://scholarsarchive.byu.edu/facpub/1284 
Peaceable Schools: Bringing Positive Behavior Support into Utah Public Education

This symposium highlights Peaceable Schools, a University-Public School Partnership currently underway in Utah County. Peaceable Schools is a prevention and intervention model for public schools K-12. This project uses Positive Behavior Support principles, which are based on the application of applied behavior analysis, focusing on the promotion of pro-social skills in the public schools. Peaceable Schools uses a positive teaching model to school-based discipline. It attempts to create and build a school culture that communicates explicit, positive expectations for students through posting school rules and consistently promoting positive behavior, rather than reacting in a punitive manner to students' inappropriate behaviors. Peaceable Schools is designed around two main levels of prevention; primary prevention, aimed at improving behavior by teaching social skills to all students in the school, and secondary prevention which involves intervening with those students screened and identified as at-risk for externalizing and internalizing disorders.

This symposium consists of four main paper presentations. It begins with a paper which gives a descriptive overview of the Peaceable Schools initiatives currently underway in 14 elementary schools throughout Utah County. This first presentation also explains the concept of Positive Behavior Support, highlights school-wide prevention efforts, and explains how such a program can be successfully designed and implemented in other elementary schools.

The second paper in the symposium describes secondary level prevention and intervention efforts being conducted in a middle school and a junior high school in Utah County. This part of the symposium focuses on school-wide screening and the interventions that occur for adolescent students identified as at-risk. It includes a description of the students' daily instruction, focusing on self-management behaviors, the furthering of social skills training, and the teaching of organizational skills.

The third paper presentation addresses the impact of the Peaceable Schools primary prevention efforts on parent, student, and staff ratings on the Indicators of School Quality (ISQ), a comprehensive survey system designed to evaluate and monitor school improvement efforts. This portion of the symposium compares the ISQ results of treatment schools with control/comparison schools which are not receiving the program. Results of the statistical analyses yielded mixed results, and varied by response group (e.g. parent, student, staff). However, the ISQ items which were more specific to the Peaceable Schools interventions yielded results more clearly in favor of the treatment schools.

The fourth component of the symposium presents the results of using the Systematic Screening for Behavior Disorders (SSBD), a teacher rating scale developed specifically for identifying elementary school students with internalizing and externalizing behaviors. This portion of the symposium examines whether the SSBD might also be effective when used as a screening measure at the secondary school level. Students' scores on the SSBD were compared with their scores on the Teacher Report Form (TRF) of the Child Behavior Checklist along with their scores on the Social Skills Rating System (SSRS). Results supported the conclusion that teachers SSBD ratings can 
be used to help identify internalizing and externalizing behaviors in middle and junior high school students.

The final portion of the symposium will be dedicated to a question and answer interchange addressing the ideas, concepts and results presented. This portion will be led by an experienced dean of education at the sponsoring university. It is hoped that the symposium will stimulate a high degree of audience participation and thus 2 hours of time is being requested. 